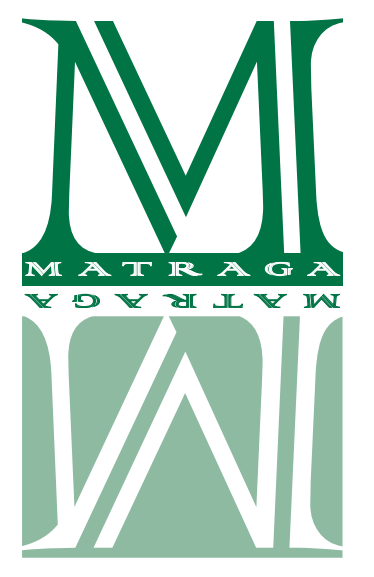

\title{
Fazer morrer e não deixar viver: discursividades sobre a morte no discurso do presidente do Brasil
}

\author{
Ana Claudia Dias Ribeiro \\ Instituto Federal de Ciências e Tecnologia de Rondônia (IFRO)/ \\ Universidade Federal do Tocantins (UFT) \\ https://orcid.org/0000-0001-9755-5915 \\ Adelto Rodrigues Barbosa \\ Universidade Federal do Triângulo Mineiro (UFTM) \\ https://orcid.org/0000-0002-5649-7357
}

\section{RESUMO}

Neste trabalho, temos como objetivo refletir sobre as discursividades que atravessam o enunciado "E daí? Lamento. Quer que eu faça o quê? Eu sou Messias, mas não faço milagre", proferido pelo presidente da República do Brasil, Jair Messias Bolsonaro e seus efeitos de sentido, na perspectiva dos fundamentos teórico-metodológicos da Análise de Discurso de linha francesa materialista. Para tanto utilizamos os pressupostos teóricos de Pêcheux e Orlandi. A escolha dessa temática ocorreu mediante a repercussão das declarações do presidente brasileiro acerca do avanço da pandemia, após o país ter sofrido um grande aumento no número de infectados e ter batido recorde em número de mortes, ultrapassando a China. Nesse sentido, mobilizamos o movimento parafrástico como dispositivo analítico, visando compreender o funcionamento discursivo do referido enunciado. A perspectiva pecheuxtiana tem como pressuposto relacionar a linguagem à sua exterioridade, representada, metodologicamente, pela situação e pelo sujeito, que são designadas de condições de produção. Dessa maneira, compreendemos como o enunciado selecionado, produz sentidos, por meio dos processos de significação instaurados no texto, descrevendo seu funcionamento, visto que para a $A D$ a língua é materialidade do discurso, portanto não se pode deixar de considerar sua relação com a historicidade. A materialidade significante, aqui descrita e analisada, permite entrever que para o sujeito enunciador, a pandemia surge como um aparato de serviço da morte aos indesejados. O que nos possibilita dizer, parafraseando Foucault, é esta a política do "fazer morrer e não deixar viver".

PALAVRAS-CHAVE: Discursividades; Morte; Paráfrase; Pandemia

Doing and Don't Let Living: Discursivities about death in the speech of the president of Brazil

\section{ABSTRACT}

This paper aims at proposing a reflection on the discursiveness running through the statement "So what? Sorry. What do you want me to do? I am the Messiah, but I do not perform miracles", by the President of the Republic of Brazil, Jair Messias Bolsonaro, as well as its effects of meaning, under the perspective of the theoretical and methodological foundations of Discourse Analysis of French materialist line. Therefore, we 
based the discussion on the theoretical assumptions by Pêcheux and Orlandi. The choice for such theme occurred through the repercussion of the Brazilian president's statements about the advance of the pandemic, after the country suffered a great increase in the number of infected people and had broken a record in number of deaths, surpassing China. In this sense, we mobilized the paraphrastic movement as an analytical device, aiming at understanding the discursive functioning of the aforementioned statement. The Pecheux perspective has the assumption of relating language to its exterior, represented, methodologically, by the situation and by the subject, which are called production conditions. Thus, it is possible to understand how the selected statement produces meanings, through the processes of signification established in the text, describing its functioning, since for Discourse Analysis, language is the materiality of the discourse, and consequently, its relationship with historicity cannot be ignored. The significant materiality, described and analyzed here, allows us to foresee that for the enunciating subject, the pandemic means an apparatus in service for the death of the unwanted, allowing us to say, to paraphrase Foucault, that this is the policy of "making people die and not letting them live".

KEYWORDS: Discursivities; Death; Paraphrase; Pandemic

\section{Introdução}

O mundo vem enfrentando a crescente propagação do novo coronavírus o que tornou-se um dos maiores desafios da humanidade, levando a Organização Mundial da Saúde (OMS) classificar a COVID-19 como uma pandemia (em 11/03/2020), devido ao seu grande poder de contágio e sua proliferação geográfica. Os primeiros casos ocorreram na China no mês de dezembro de 2019, no mês de março já tinha atingindo mais de 200 países e territórios, apresentando índices crescentes de números de casos de contágio e de mortes. Embora, a OMS tivesse solicitado aos governos dos diversos países a adotar medidas de contenção do vírus, alguns governantes continuavam sem agir, efetivamente, contra o problema. No Brasil, o registro do primeiro caso de contaminação pelo novo coronavírus ocorreu no final de fevereiro de 2020 e em março, tivemos o registro da primeira morte pela doença. A forma como o presidente brasileiro (2018-2022), Jair Messias Bolsonaro, conduz o enfrentamento à pandemia tem provocado desaprovação e críticas por parte de várias instituições brasileiras, dentre elas a presidência da Comissão de Direitos Humanos da Câmara dos Deputados $(\mathrm{CDHM})^{1}$. A referida comissão realizou várias denúncias às autoridades das Nações Unidas contra o presidente Bolsonaro, tendo como base sua ação de não atender as recomendações da OMS, como fazer o uso de máscaras, evitar aglomerações, negação da gravidade da pandemia e falta de gerenciamento sanitário. Segundo a CDHM, as ações do governo federal violam os direitos humanos, além de fragilizar ainda mais a parcela da população mais vulnerável, diante da pandemia. Esse fato levaram os relatores da ONU, no dia 29 de abril de 2020, a condenarem as medidas adotadas pelo governo do Brasil durante a pandemia da COVID-19.

Assim, com a pandemia avançando no país, aumentando cada vez mais o número de infectados e o número de mortes diárias batendo recordes, Bolsonaro causa indignação por seus pro-

\footnotetext{
1 https://www2.camara.leg.br/atividade-legislativa/comissoes/comissoes-permanentes/cdhm/noticias/onu-critica-austeridade-mal-orientada-do-governo-brasileiro-no-contexto-da-pandemia
} 
nunciamentos e declarações. Foram estas questões que nos motivaram a abordar essa temática. Neste trabalho, portanto, iremos refletir sobre as discursividades que atravessam o enunciado "E daí? Lamento. Quer que eu faça o quê? Eu sou Messias, mas não faço milagre", proferido pelo presidente Bolsonaro e seus efeitos de sentido. A partir dos fundamentos teórico-metodológicos da Análise de Discurso de linha francesa, (AD) a qual nos filiamos. Nesse sentido, mobilizaremos o movimento parafrástico como dispositivo analítico, visando compreender o funcionamento discursivo do referido enunciado.

A perspectiva pecheuxtiana tem como pressuposto relacionar a linguagem à sua exterioridade, representada, metodologicamente, pela situação e pelo sujeito, que são designadas de condições de produção. Dessa maneira, buscamos compreender como o enunciado selecionado, produz sentidos, mostrando os processos de significação instaurados no texto e descrevendo seu funcionamento, visto que para a $\mathrm{AD}$ a língua é materialidade do discurso, portanto não se pode deixar de considerar sua relação com a historicidade.

De acordo com Orlandi (2012) existem três momentos importantes que precisam ser considerados, no processo de produção discursiva, são eles: a constituição, a formulação e a circulação. E, ao mesmo tempo que se inter-relacionam são inseparáveis. A constituição diz respeito à memória do dizer, ou seja, relaciona-se ao contexto histórico-ideológico. No que se refere à formulação, encontra-se ligada às condições de produção, já a circulação diz respeito ao "meio" onde o discurso circula.

Na perspectiva discursiva, os sentidos não estão prontos, já dados, e sim, construídos. Dessa maneira, a linguagem está sujeita às falhas, ao equívoco constitutivo no processo de significação. Os sentidos estão à deriva, navegam pela memória e se manifestam pelos fios do dizer, mas não de forma plena, e sim, de acordo com as condições de produção. Cabe ao analista de discurso desconstruir sentidos cristalizados para mostrar como o discurso produz sentidos diversos.

A AD permite-nos "instalar em uma posição materialista" e, assim, nos "inscrever em uma posição que privilegia a ideia de processo e de articulação entre estrutura e acontecimento num batimento" (ORLANDI, 2012, p.183). Em outras palavras, trabalhar com a AD é estar em um movimento que vai do tema - objeto de estudo - à descrição e análise dos recortes, enfrentando a opacidade do texto, da linguagem, para retornar ao tema e à teoria para revisões e reformulações. Desse modo, para a $\mathrm{AD}$, a linguagem não é transparente e o sentido não é conteúdo. Os sentidos não estão nas palavras, mas nas relações que se estabelecem no discurso, este, entendido na perspectiva de Pêcheux como:

[u]ma sequência linguística de dimensão variável, geralmente superior à frase, referida às condições de produção que determinam a produção dessa sequência em relação a outros discursos, sendo essas condições propriedades ligadas ao lugar daquele que fala e àquele que o discurso visa, isto é, àquele a quem se dirige formal ou informalmente, e ao que é visado através do discurso. (PÊCHEUX, 2015, p. 214)

Assim, interessa-nos saber quem fala, de onde fala, para quem fala, em quais condições o discurso foi proferido. O que permite distinguir produção de diferentes sentidos pelos sujeitos em diferentes condições de produção ou situações é a Formação Discursiva (FD). Con- 
sidera-se que os sentidos não existem em si, mas à medida que se inscrevem em uma FD ou em outra.

Entendemos por FD "aquilo que, numa formação ideológica dada, isto é, a partir de uma posição dada numa conjuntura dada, determinada pelo estado da luta de classes, determina o que pode e deve ser dito" (PÊCHEUX, 2014 [1975], p. 147), o que significa que os sujeitos ocupando posições discursivas diferentes podem produzir diferentes sentidos.

Chamamos atenção para o fenômeno de metaforização dos sentidos que vem ocorrendo nos discursos políticos vinculados às posições de poder neoliberais e de extrema-direita, observados a partir das eleições de 2018. Tomemos como exemplo, os deslocamentos e ressignificação das palavras ditadura, democracia e opositores, na atualidade. O termo ditadura vem sendo utilizado para se referir à esquerda (oposição). Enquanto para se referir ao sistema que o "atrapalha" a governar, utiliza-se a palavra democracia. Todos os opositores do governo, são opositores do Brasil. De acordo com Mariani (2019, p. 271), podemos identificar nesses gestos de interpretação "a construção de verdades locais [...] cuja materialidade linguageira tem sede em sítios de significação [...] negativizados, visando convocar a sociedade para uma tomada de posição de negação, aversão e repulsa a qualquer sentido positivo atribuído à palavra."

A constituição, formulação e circulação constituem três importantes momentos no processo de elaboração do discurso. O primeiro, a constituição, corresponde à memória do dizer, ou seja, ao interdiscurso que compreende os dizeres já ditos e esquecidos; o segundo diz respeito a formulação (dimensão do intradiscurso) é quando ocorre a textualização, se "dá corpo aos sentidos" (ORLANDI, 2005, p. 9), envolve, portanto, as condições de produção; o terceiro, trata-se da circulação, isto é, o meio por onde os sentidos se formulam e como circulam.

Após essa breve justificativa e apresentação da temática deste trabalho, seguiremos para outras seções, assim organizadas: na seção 2, considerando que a $\mathrm{AD}$ tem como pressuposto relacionar a linguagem à sua exterioridade, representada, metodologicamente, pela situação e pelo sujeito, trataremos da formulação escolhida e suas condições de produção; na seção $3 \mathrm{~A}$ partir de Foucault, enfocaremos o deslizamento metonímico da palavra "morte" nas discursividades que circulam nas FDs religiosa e política; na seção 4, abordamos questões sobre o lugar discursivo e questões de identificação do sujeito do discurso com a forma-sujeito; na seção 5, procedemos com a descrição e análise da formulação selecionada mostrando os processos de significação instaurados no texto, descrevendo seu funcionamento e por fim traçamos algumas considerações acerca do tema discutido.

\section{A formulação e suas condições de produção}

É por meio da formulação que a linguagem ganha vida, se materializa, os sentidos se instauram, nas palavras de Orlandi "formular é dar corpo aos sentidos" (2012, p. 9). Dito de outra forma, a formulação é o momento em que o sujeito materializa seu dizer em forma de linguagem (verbal ou não verbal). A AD possui procedimentos específicos, baseados em noções e princípios. Para realizar uma análise discursiva se faz necessário a articulação da estrutura 
(linguagem) e o acontecimento (momento sócio histórico) em que o discurso foi produzido, ou seja, suas condições de produção.

Visto que o princípio fundamental do método é relacionar a linguagem à sua exterioridade, ou seja, às suas condições de produção, se faz necessário compreender as condições de produção da materialidade em análise, observando sua situação discursiva imediata, mas também uma conjuntura mais ampla sócio histórica e ideológica.

A materialidade, selecionada, para esta análise, surgiu em meio ao acontecimento, pandemia, que é um fato histórico que demanda por interpretação, conforme Henry (2014, p. 55), "não há 'fato' ou evento histórico que não faça sentido, que não peça interpretação, que não reclame que lhe achemos causas e consequências". Quando um acontecimento histórico passa a ser discursivizado, surge, então, o acontecimento discursivo que, de acordo com Pêcheux (2002 [1983]), ocasiona uma ruptura com os sentidos latentes e instaura uma nova ordem discursiva. Assim, a pandemia do novo coronavírus não afeta somente a saúde pública, mas todas as formas de organização da sociedade, ela domina as discursividades de todas as classes sociais, instaura uma série de incertezas, faz com que o presente e o futuro reflitam essa ameaça mundial e evidencia a contradição capitalismo X vida. Nesse sentido, as posições sujeitos e, claro, as palavras e os sentidos são afetados pela metaforização da pandemia, que se encontra simbolizada por meio da linguagem. Quando falamos em metáfora aqui, estamos nos referindo à perspectiva da AD. Para Orlandi (2015), a metáfora consiste em como as palavras falam umas com as outras, produzindo transferências, equívocos, silenciosa ou explicitamente.

Na perspectiva discursiva, a ideologia interpela o indivíduo em sujeito, naturalizando alguns sentidos e interditando outros. As mídias digitais têm se mostrado um dos meios mais eficiente no que diz respeito à construção de sentidos referentes à política nacional e na (re)produção dos discursos que circulam nas mídias digitais. O enunciado que recortamos para esta análise circulou em uma matéria jornalística publicada no site $\mathrm{G}^{2}$. É interessante observar que o enunciado em questão circulou também em outros sites de notícias e obteve grande repercussão nas redes sociais e TVs no Brasil e no mundo.

Enquanto a China, país de origem da pandemia, atingia o quantitativo de 4.643 casos de morte por COVID-19, o boletim informativo do Ministério da Saúde registrava o número de 5.017 óbitos ocorridos no Brasil, em decorrência do coronavírus. O presidente Jair Bolsonaro, na portaria do Palácio da Alvorada, disse: "E daí? Lamento. Quer que eu faça o quê? Eu sou Messias, mas não faço milagre”. Essa formulação ocorreu, logo após uma jornalista dizer ao presidente que o número de brasileiros mortos ultrapassava os números de mortos da China, em decorrência da COVID-19. Nessa formulação, o sujeito assume, inicialmente, um tom de desprezo, no instante seguinte um sentimento, depois uma interrogação demonstrando não ter responsabilidade sobre os eventos, para assumir uma posição de divindade, fugindo do seu papel de presidente, e logo em seguida nega possuir poderes divinos.

\footnotetext{
2 https://g1.globo.com/politica/noticia/2020/04/28/e-dai-lamento-quer-que-eu-faca-0-que-diz-bolsonaro-sobre-mortes-por-coronavirus-no-brasil.ghtml Acesso em: 25/05/2020
} 
A discursivização dos profissionais da saúde e a mídia, foram no mesmo sentido, no primeiro momento, tentar tranquilizar a população. Era uma doença com grande poder de contágio e baixa letalidade. As vítimas fatais do coronavírus, seriam pessoas idosas, ou indivíduos com alguma comorbidade. Em poucos dias, o cenário mudou, e o coronavírus, causou a morte de recém-nascidos, crianças, jovens, adultos e idosos. O Sistema Único de Saúde - SUS, sucateado e ineficiente, colapsou. As disputas políticas dos administradores públicos, as notícias falsas, falsificadores de produtos básicos de higiene preventiva, colaboraram para um cenário caótico por todo país.

Desde o surgimento do primeiro caso de infecção causada pelo coronavírus Sars-CoV 2, mais tarde conhecido como COVID-19, na China e o primeiro caso confirmado no Brasil, no dia 26/02/2020, a velocidade de contaminação e letalidade da doença não provocaram mudanças nas discursividades negacionistas do sujeito presidente da República a respeito da doença. O que causa estranheza no enunciado é justamente ele ter sido proferido pelo chefe máximo do país, cuja função é garantir a saúde e bem-estar da nação, como prevê a Constituição Federal Brasileira em seu Art. 196: "A saúde é direito de todos e dever do Estado, garantido mediante políticas sociais e econômicas que visem à redução do risco de doença e de outros agravos e ao acesso universal e igualitário às ações e serviços para sua promoção, proteção e recuperação". No entanto, seu discurso permite entrever justamente o contrário, como se o sujeito na posição de presidente não tivesse meios necessários para abrandar os efeitos da pandemia.

A alternativa recomendada pela OMS para evitar a proliferação do vírus foi de adotar o isolamento social. Alternativa que mostrou resultados positivos em países como a Itália e a Espanha que realizaram bloqueios rigorosos por isso obtiveram uma estabilização na expansão da doença. Recomendação esta que o presidente brasileiro considerou desnecessária. No início, a lógica negacionista da gravidade, era para poupar a população do pânico, do caos mundo afora, o presidente ao se referir à pandemia utilizou as seguintes formulações: "gripezinha", "histeria", e disse que o coronavírus estava sendo "superdimensionado" e que a mídia propagava "fantasias". Em outra ocasião, ao ser questionado sobre o número de óbitos causados pela COVID-19, respondeu, "não sou coveiro". O discurso do presidente, demonstra pouco apreço pela vida, e não sentimento de compaixão por pessoas que tenham qualquer comorbidade. "Vão morrer alguns pelo vírus? Sim, vão morrer. Se tiver um com deficiência, pegou no contrapé, eu lamento".

Cabe salientar que para a $\mathrm{AD}$ os sentidos não existem em si, mas à medida que se inscrevem em uma FD ou em outra, sempre em relação a. Desse modo, os sujeitos ocupando posições discursivas diferentes podem produzir diferentes sentidos, de forma que o sentido sempre pode ser outro. Uma maneira de mostrar outros possíveis sentidos de um enunciado é por meio da paráfrase, que se trata da substituição, que evidencia outro sentido mobilizando o efeito metafórico para pensar a tensão mesmo/diferente. De acordo com Orlandi, "dizemos o mesmo para significar outra coisa e dizemos coisas diferentes para ficar no mesmo sentido" (ORLANDI, 1993, p. 98). Nesse movimento, pode fazer surgir outros sentidos, conforme sejam as condições de produção da materialidade discursiva. Veremos na próxima sessão como os sentidos da palavra "morte" podem mudar, conforme sua circulação em uma determinada FD. 


\section{A morte no discurso religioso e no discurso político}

Podemos observar o efeito polissêmico que ocorre com a palavra "morte" ela pode não ser individual, mas coletiva. Assim, por um processo de transferência de sentidos ela produziria um efeito de extinção da raça, do fim do mundo. Há um deslizamento metonímico da palavra de uma formulação para outra mudando o sentido. A palavra vai mudando de sentido dependendo de quem, onde, como, para quem diz, etc.

Neste trabalho, consideramos o que ressalta Althusser (1980) acerca da religião como aparelho ideológico religioso (AIE) que funciona, predominantemente, pela coerção ideológica e compete com os outros AIE no mesmo objetivo: a reprodução das relações de produção, ou seja, na reprodução das relações de trabalho na sociedade capitalistas.

A AD considera ser a ideologia que transforma o indivíduo em sujeito (ORLANDI, 2015) consoante ao que postula Althusser:

(...) se considerarmos que a ideologia religiosa realmente se dirige aos indivíduos a fim de 'transformá-los em sujeitos', interpelando o indivíduo Pedro para fazer dele um sujeito, livre para obedecer ou desobedecer ao apelo, isto é, aos mandamentos de Deus (...) Depreende-se, pois, que a interpelação dos indivíduos como sujeitos pressupõe a existência de um Outro Sujeito, Único e Central, em cujo nome a ideologia religiosa interpela todos os indivíduos como sujeitos. (ALTHUSSER, 1980. p. 106-107)

Para os sujeitos pertencentes a uma FD na qual predomina a ideologia religiosa que tem como base moral e cultural fundante, o pensamento Cristão do Ocidente, em que o mundo é obra de um criador, vida/morte possuem caráter divino. Seguindo ainda este pensamento, a morte é uma consequência do pecado. "Porque o salário do pecado é a morte, mas o dom gratuito de Deus é a vida eterna, por Cristo Jesus nosso Senhor." (Romanos, 6:23) ${ }^{3}$. Então a morte teria relação com pecado, resultado das atitudes dos indivíduos nas relações sociais. Este discurso foi bastante recorrente nas redes sociais, logo com a chegada do coronavírus ao Brasil. Algumas publicações mostravam, vídeos ${ }^{4}$ e imagem do desfile da escola de samba paulista, Gaviões da Fiel, em que o diabo subjuga Jesus. Essas postagens traziam as legendas, "achou que ia ficar de graça?" ou "a conta chegou".

A discursivização que busca atribuir culpado para justificativas em momentos de catástrofes naturais como pandemias, faz parte de uma memória discursiva que incide na história de maneira recorrente. O sujeito interpelado pela ideologia religiosa, atribui à vontade divina tudo aquilo para qual não consegue explicações, tais como catástrofes naturais e doenças. Essa discursivização perpassa a história das tragédias da humanidade. Nesse sentido, formulações semelhantes existem desde erupções vulcânicas, peste-negra, gripe espanhola ${ }^{5}$, como podemos observar no excerto a seguir:

\footnotetext{
${ }^{3}$ https://www.bibliaonline.com.br/act/rm/6/23 Acesso em 23/06/2020

4 https://www.facebook.com/alison.bernardino.56/videos/215713659747357/UzpfSTEwMDAxMDA4MDk2MjUy0ToxMTA1MDYONzE50DM5NTUw/?|st=1125865838\%3A100010080962529\%3A159179811 Acesso em 26/06/2020

${ }^{5}$ https://www.scielo.br/scielo.php?pid=S0104-87752009000200005\&script=sci_abstract\&tlng=pt Acesso em: 09/10/2020
} 
O homem subitamente derrubado por furúnculos febre era, simplesmente, um homem derrubado pela vontade de Deus. Ou, pior ainda, pela ira divina. Não parecia haver diferença de significado entre essa peste e a erupção do Monte Etna, em 1333, as terríveis tempestades que destruíram as lavouras francesas em 1336, as nuvens de gafanhotos que atacaram as colheitas em 1337 e 1338, as grandes enchentes do Reno em 1342 ou os terremotos que devastaram a Itália em 1347. Nenhuma diferença, exceto pelo fato de um Deus não aplacado parecia haver-se irado mais que nunca (FRIEDRICH, 2000, p. 143).

Não está diferindo com a COVID-19, para àqueles que se inscrevem na formação discursiva religiosa (poderíamos, talvez, dizer neopentecostal), a ocorrência de fenômenos naturais (como as tempestades, as nuvens de gafanhotos), fazem sentido se relacionados ao divino. Desse modo, seriam formas com as quais o criador do universo demonstraria seus aborrecimentos em relação às ações de suas criaturas. Então, esse sujeito deveria buscar consolo na morte, assumindo uma posição de "aceitação", em que o padecimento pela doença é só um momento transitório, a passagem para a "vida eterna”. Nesse sentido, a morte não possui o caráter de extinção do sujeito, mas é algo transitório, uma passagem. O homem cristão teria uma premiação, o não cristão receberia um castigo. "Eu sou a ressurreição e a vida. Aquele que crê em mim, ainda que morra, viverá; e quem vive e crê em mim, não morrerá eternamente." (João 11:25-26) .

O AIE político na busca de poder ou permanência no poder tem ancoragem histórica na força, na violência. Michel Foucault (2005[1976]), inverte o aforismo do comandante militar, Carl Von Clausewitz 7 , “o poder é a guerra, é a guerra continuada por outros meios. E, neste momento, inverteríamos a proposição de Clausewitz e diríamos que a política é a guerra continuada por outros meios. (FOUCAULT, 2005[1976], p. 22). Nessa perspectiva, trata-se de uma guerra silenciosa, na qual as armas do Estado, nestas batalhas, são as políticas públicas que operam o silenciamento de grupos minoritários na composição do poder. No conjunto de suas reflexões, Foucault traz o conceito de biopoder, que para ele, consistia nas práticas de gestão e regulação de vidas humanas, referentes ao período moderno, a partir das políticas públicas em áreas essenciais para a sobrevivência como a saúde de determinados grupos sociais, o Estado determina quem irá "fazer viver e deixar morrer".

Em Foucault, encontramos um conceito que traz outra possibilidade de interpretação sobre a morte no discurso político, o racismo de estado. Este funciona de forma difusa na sociedade, às vezes não é percebido por parte de seus membros. O racismo de Estado ou estrutural está presente no cotidiano das pessoas, seja negro ou índio, etc. Os protocolos médicos, elaborados pelos Ministério da Saúde são elaborados de forma que possam omitir a letalidade de determinadas doenças, assim não há necessidade de políticas públicas em favor de determinados grupos. Por exemplo, a não testagem da população acometida por sintomas de COVID-19, cria uma aceleração de mortes por síndrome respiratória aguda. Essa maquiagem nos resultados esconde a gravidade da pandemia. Para Foucault, o racismo de Estado é:

\footnotetext{
${ }^{6}$ https://www.bibliaon.com/morte/ Acesso em: 09/10/2020.

7 Carl Phillip Gottlieb von Clausewitz (1780 - 1831) foi um general alemão. Autor do livro Da Guerra, foi um estrategista e teórico da guerra.
} 
Perpetrado por nossas sociedades, distingue-se do tradicional ódio entre indivíduos, consistindo em um modo de purificação da população através da eliminação de determinados grupos étnicos. Um poder exercido por estruturas administrativas e de governo, que pressupõe a existência de um vínculo intrínseco entre a prosperidade e o extermínio. Deve-se entender esse extermínio não apenas como a derradeira aniquilação física, mas também "a morte política, a expulsão, a rejeição etc." (FOUCAULT, 1999, p. 306 apud FURTADO, CAMILO 2016, p.09).

Em vista disso, o Estado coloca em funcionamento um grande aparato a serviço da morte dos indesejados para os grupos detentores do poder. "A relação da morte e a riqueza e a pobreza diz respeito à demografia, à desigualdade diante da doença e sobretudo da peste" (ARIÈS, 2017, p. 103). Acrescentemos a isso o AIE escolar por meio da precarização do ensino, que forma uma massa de trabalhadores submetidos a baixos salários e condições de trabalho insalubres, análogas à escravidão. Uma massa humana vivendo nas grandes periferias, sem saneamento básico, sem acesso à saúde e à educação, a mercê de ações arbitrárias das forças policiais, que batem e matam sem serem responsabilizados. Os povos indígenas que vivem em constantes conflitos com grandes latifundiários, madeireiros e garimpeiros, lutas entre forças desiguais. Todas essas negações de direitos básicos à vida, para dignidade humana são práticas do Estado sobre o direito de vida e morte. Dessa maneira, o Estado tem maior influência sobre quem, quando e quantos devem viver ou morrer.

Na próxima sessão, veremos como ocorre a identificação do sujeito do discurso com o lugar discursivo e também com a posição-sujeito, para entender sua relação com o movimento de sentidos das palavras nas FDs.

\section{Do lugar discursivo}

$\mathrm{Na}$ perspectiva discursiva a qual nos filiamos, o lugar social diz respeito à relação do indivíduo, sujeito empírico, com a formação social historicamente situada, ou seja, trata-se da condição sócio histórica do indivíduo. Já o lugar discursivo está para a identificação do sujeito do discurso com a forma-sujeito que se conecta com o lugar social. Segundo Grigoletto,

[o] sujeito do discurso, ao se inscrever em um determinado lugar discursivo, vai se relacionar tanto com a forma-sujeito histórica e os saberes que ela abriga quanto com a posição-sujeito. Assim, a relação do sujeito enunciador com o sujeito do saber e, consequentemente, com a posição-sujeito é deslocada para as relações de identificação/determinação do lugar discursivo tanto com a forma-sujeito histórica (ordem da constituição/do interdiscurso), quanto com a posição-sujeito (ordem da formulação/do intradiscurso)" (GRIGOLETTO, 2005, p.7).

Ou seja, a posição-sujeito é o movimento de (des)identificação do enunciador, afetado pela forma-sujeito do discurso de divulgação científica, por exemplo, em relação às posições possíveis, de acordo com a FD (religiosa, científica, política, senso comum, etc.). Ocorre que a sobredeterminação é suscetível a falhas e pode ser rompida pela incidência do real, fazendo com que o sujeito se filie a outra FD. Esse desencaixe pode ser provocado por variados fatores entre eles: 
formação ideológica, formação discursiva e/ou formação imaginária. É preciso lembrar que os sentidos estão em constante disputa.

Utilizaremos como dispositivo de análise os processos parafrásticos e polissêmicos operacionalizados no processo descritivo-interpretativo. Dado que, as paráfrases permitem identificar indícios do processo de produção de sentidos, possibilitando apontar como o enunciador se posiciona e se constitui como sujeito histórico, a partir da relação entre o já dito e o que está se dizendo, dito de outro modo, entre a constituição do sentido e sua (re)formulação.

De acordo com Mittmann:

[é] trabalho do analista "Escarafunchar o texto, levantar os ditos, mas principalmente arriscar-se aos não-ditos, presença-ausência. E então nos deparamos com dois tipos de não-ditos constitutivos do dito: aqueles possíveis a partir de determinada identificação com uma formação discursiva (parafrásticos) e aqueles impossíveis (polissêmicos) (MITTMANN, 2010, p. 89).

Dessa forma, mostraremos o funcionamento da linguagem nas diferentes possibilidades de efeitos de sentido, apontando para uma regularidade discursiva dentro da FD, pela qual o sujeito se identifica. Não podemos esquecer que no processo de formulação do dizer, o sujeito é afetado por dois esquecimentos: o esquecimento ideológico em que o sujeito tem a ilusão de que é a origem do dizer e o esquecimento da ordem da enunciação na qual o sujeito acredita ter o controle sobre os sentidos e que o outro entende, exatamente, da mesma forma que ele enunciou (PÊCHEUX, 2014 [1975]).

No processo de enunciação, ocorre o que podemos chamar de "jogo de projeções" em que o enunciador ao se identificar com uma determinada FD "adere" aos sentidos que nela circulam e ao modo de percepção da realidade, no entanto. Essa "adesão" não se dá de forma consciente, embora o enunciador acredite ser livre para fazer a opção. Dito de outra forma, são as formações imaginárias que

[d]esignam o lugar que A e B se atribuem cada um a si e ao outro, a imagem que eles se fazem de seu próprio lugar e do lugar do outro. Se assim ocorre, existem nos mecanismos de qualquer formação social regras de projeção, que estabelecem as relações entre as situações (obviamente definíveis) e as posições (representações dessas situações) (PÊCHEUX, 2014 [1969], p. 82).

Assim, o enunciado proferido pelo sujeito (presidente) pode produzir diferentes efeitos de sentidos entre seus interlocutores, a depender da FD a qual se filiam seus interlocutores. Isso nos leva a refletir sobre a noção de efeito metafórico, que é uma característica inerente a língua, que possibilita o deslize, para as diferentes formas de "dizer" ou formular. Na sessão a seguir, apresentaremos nosso processo analítico sobre a materialidade selecionada, procedendo com a descrição e interpretação visando compreender seu funcionamento discursivo.

\section{Discursividade sobre a morte no discurso do presidente}

Na perspectiva a qual nos inscrevemos, a interpretação é tida como possível gesto de leitura que é determinado pelo dispositivo teórico por meio do qual buscamos compreender como um 
objeto simbólico produz sentidos. Destarte, mobilizamos o movimento parafrástico como dispositivo analítico, visando compreender o funcionamento discursivo da seguinte formulação: "E daí? Lamento. Quer que eu faça o quê? Eu sou Messias, mas não faço milagre”. É próprio ao método fazer um batimento entre descrição e interpretação. Isso porque há uma injunção à interpretação, diante de qualquer objeto simbólico, somos impelidos a significar.

Para $\mathrm{AD}$ o discurso é o efeito de sentidos entre locutores, no caso em questão os locutores são: o presidente e a jornalista. No início da formulação, temos a expressão "e daí" utilizada para indicar uma conclusão em decorrência do que foi dito anteriormente. O que antecedeu a formulação em questão foi a seguinte afirmação feita por uma jornalista dirigindo-se ao presidente: "A gente ultrapassou o número de mortos da China por COVID-19". Naquele dia, o Brasil atingiu a marca de 5.017 mortes por coronavírus, número superior ao registrado na China. O enunciador sujeito-falante (presidente) estabelece o diálogo com a sua interlocutora (jornalista) interrompendo-a, logo após a contextualização da questão, quando ela tentava formular a pergunta a respeito do plano de combate ao coronavírus. O enunciador inicia sua formulação retomando o dizer da repórter, utilizando a expressão “E daí?”, trata-se de uma expressão popular que significa indiferença, escárnio, falta de interesse e é considerada uma resposta grosseira. Ao ser informado sobre o número de mortes, o presidente demonstra indiferença, reage grosseiramente, como se as questões de saúde pública do país não fossem sua responsabilidade.

Em seguida, temos uso do verbo lamentar na primeira pessoa (lamento), que deixa entrever uma tentativa de amenizar seu desprezo diante do dizer de seu interlocutor. Na sequência, o locutor se volta para o interlocutor e cobra dele "Quer que eu faça o quê?” terceiriza sua responsabilidade, na posição sujeito de presidente de uma das maiores nações do mundo, caracterizando, assim, uma mera pergunta retórica, qual ele mesmo reponde: "Eu sou Messias, mas não faço milagre". O enunciador se posiciona, assumindo o dizer com o uso do pronome "eu" e, ainda, faz uma brincadeira explorando a polissemia da palavra "Messias" que pode se referir tanto ao seu nome próprio (Jair Messias Bolsonaro) quanto ao "Messias" bíblico, o filho de Deus.

A última parte da formulação é constituída por uma oração coordenada adversativa: "Eu sou Messias, mas não faço milagre", e, embora seja utilizada a conjunção adversativa "mas", sua ocorrência denota explicação. Tal formulação remete ao não-dito: "Não está ao meu alcance fazer algo a respeito, pois, não tenho poderes sobrenaturais". Seria, portanto, descabido cobrar dele uma tomada de atitude sobre o aumento do número de mortes por COVID-19 no Brasil, superando o índice dos chineses. A formulação, em análise, materializa uma forma do enunciador se esquivar de sua omissão, que nos faz refletir a respeito da formulação imaginária, conforme Pêcheux ([1969], 2014, p. 82): “quem é ele para me falar assim?” A indignação por parte de grande parte da população, diante de tal discursivização governamental, remete a um desencaixe das atitudes do presidente (nos referimos ao lugar discursivo), com a imagem constituída no imaginário popular. Esperava-se, do chefe do executivo, atitudes concretas e objetivas, baseada no saber científico e em consonância com os outros entes da federação, visando atender às necessidades da população.

No ato de dizer, estabelecemos escolhas, silenciando outras possibilidades de dizer, porém, o que foi silenciado, ou seja, o não-dito também significa, pois, mantém sentido com o que foi 
dito. Nessa perspectiva, na formulação analisada, dentre outros efeitos de sentido possíveis, temos os seguintes:

1) Não me interessa! "Não posso fazer nada." Eu não sou Jesus, por isso "não posso ressuscitar os mortos".

2) "É lamentável. Eu asseguro" que tomaremos todas as medidas para "evitar" que os "números" continuem "aumentando".

3) Não é problema meu. "Todo mundo morre". É natural. "Eu não sou" Deus para evitar as mortes.

4) Infelizmente, os índices de morte atingiram esse quantitativo. "Não mediremos esforços" junto aos ministérios da saúde e economia para traçar estratégias, "visando o bem de todos" os brasileiros.

FD 1: posição-sujeito 1: os dados acerca do aumento do número de mortes não têm importância e, sobre isso, nada pode ser feito.

Posição-sujeito 2: lamenta as mortes, mas todo mundo morre, a prioridade é a economia. FD 2: lamenta o número de mortos e não medirá esforços, visando o bem de todos.

O funcionamento da FD 1, posição sujeito 1, pode conduzir à teorização sobre o pré-construído, advindo da ideologia religiosa em vida/morte possuem caráter divino, e, ainda, a morte é uma consequência do pecado, faz parte do ciclo da vida. Por conseguinte, temos aí um efeito de evidência que produz o apagamento do papel do Estado em assumir a responsabilidades de suas ações, para contornar o problema, colocando o interesse público acima dos interesses eleitorais.

Já na FD 1: posição-sujeito 2, deixa entrever a morte na perspectiva do discurso político, o racismo de estado, em que o governo federal usa a pandemia a serviço da morte dos indesejados, que pode ser observado nos casos em que ele minimizou a pandemia, divulgou informações incorretas, se posicionou contra o distanciamento social e se mostrou indiferente ao número de mortos. Aliás, a pandemia potencializou os impactos da emenda constitucional 2016, defendida pelo presidente, que limitou os gastos públicos por 20 anos.

A negação chama atenção para o discurso outro, que foi impedido de ser formulado, de ser colocado em circulação. Na formulação: “Eu sou Messias, mas não faço 'milagre”” o sujeito falante estabelece uma censura que diz respeito de sua própria posição discursiva. No dicionário ${ }^{8}$ milagre é definido como "ato ou acontecimento fora do comum, inexplicável pelas leis da natureza”, o uso dessa palavra refere-se a trazer os mortos à vida ou evitar novas mortes? Enquanto na paráfrase: "Eu não sou Jesus, por isso 'não posso ressuscitar os mortos”, o sujeito falante apaga a posição social ele ocupa e que lhe permite evitar novas mortes, visto que não há como trazer os mortos de volta à vida. Podemos, ainda, recuperar outras formas de dizer silenciadas. "Não posso liberar recursos' para construir hospitais, comprar respiradores, construir leitos de UTI, pagar o auxílio emergencial de 600 reais, além de manter empregos, respeitar a dor das pessoas e valorizar os trabalhadores da saúde".

\footnotetext{
${ }_{8}$ http://michaelis.uol.com.br/busca?id=yV5A3 Acesso em: 28/09/2020
} 
Podemos afirmar que tudo o que Bolsonaro deixa de falar (formulações 2 e 4) por não ser permitido, a partir de uma formação discursiva com a qual ele se identifica, na qual circulam o negacionismo científico e o discurso neoliberal, que prioriza a economia em relação à saúde, potencializando as diferenças sociais e a exposição da população mais vulnerável ao Coronavírus. Assim, o governo coloca em prática o racismo de estado. Não reconhecendo o poder de letalidade da doença, o que justifica sua omissão em adotar políticas públicas em favor de determinados grupos sociais, que têm os riscos de contrair a doença potencializados devido às condições sociais em que vivem.

\section{Considerações}

A partir da perspectiva discursiva de orientação pecheuxtiana, buscamos compreender como o enunciado selecionado, produz sentidos, mostrando os processos de significação instaurados no texto, descrevendo seu funcionamento. Vimos funcionar o trabalho da memória, na formulação do dizer, que ao enunciar $\mathrm{x}$, silencia $\mathrm{y}$, diferentes sentidos, como é próprio da linguagem abrir-se para a dispersão e para heterogeneidade.

Mostramos, por meio dos processos parafrásticos e polissêmicos, os indícios do processo de produção de sentidos, que nos possibilitou apontar a tomada de posição do sujeito-enunciador, a partir do lugar discursivo em que se reconhece como sujeito. Desse modo, o sujeito projeta sua própria imagem e a dos seus interlocutores, imbuído por um efeito ideológico de que é livre para enunciar; que possui controle sobre o que diz e sobre o que os outros vão interpretar.

A materialidade significante, aqui descrita e analisada, permite entrever o lugar discursivo-presidente, enquanto sujeito que produz formulações que revelam seu descrédito na ciência, o desinteresse em tomar conhecimento do quantitativo de vidas perdidas evidenciado se importar mais com a economia do país do que com a população em si, mostrando que as políticas de morte, como o racismo de estado, atingem grupos específicos da população relacionadas a classe, raça/cor e etnia. Para este sujeito enunciador e detentor do poder a pandemia surge como um aparato de serviço da morte aos indesejados. Parafraseando Foucault é esta a política do "fazer morrer e não deixar viver".

Por fim, esperamos proporcionar uma leitura, que possibilite compreender como se realizam, na história, as relações de poder, dominação e exploração. Empreendendo uma leitura para além do nível meramente linguístico, que alcance o funcionamento da linguagem, não como um simples texto, mas com o objeto discursivo. Para isso, buscamos relacionar nossos gestos de interpretação com as relações sócio-históricas e as ideologias presentes na sociedade no processo de construção dos sentidos.

\section{REFERÊNCIAS}

ALTHUSSER, Louis. Ideologia e aparelhos ideológicos de Estado. 3 ed. Lisboa: Editorial Presença/Martins Fontes, 1980. 
ARIÈS, Phillippe. História da Morte no Ocidente: da Idade Média aos nossos tempos. Rio de Janeiro RJ: Nova Fronteira, 2017.

BERTUCCI, Liane Maria. A onipresença do medo na influenza de 1918. Dossiê: Influenza Espanhola, Varia hist. 25 (42), Dez, 2009. https://doi.org/10.1590/S0104-87752009000200005 Disponível em: https://www. scielo.br/scielo.php?pid=S0104-87752009000200005\&script=sci_abstract\&tlng=pt Acesso em: 09 out. 2020.

Bíblia Online. Disponível em: https://www.bibliaonline.com.br/acf/rm/6/23 Acesso em: 23 jun. 2020.

Bíblia Online. Disponível em: https://www.bibliaon.com/morte/ Acesso em: 09 out. 2020.

Comissão de Direitos Humanos e Minorias. Disponível em: https://www2.camara.leg.br/atividade-legislativa/comissoes/comissoes-permanentes/cdhm/noticias/onu-critica-austeridade-mal-orientada-do-governobrasileiro-no-contexto-da-pandemia Acesso em: 20 maio 2020.

BRASIL. Constituição (1988). Constituição da República Federativa do Brasil. Brasília, DF: Senado Federal, 1988. Disponível em: http://www.planalto.gov.br/ccivil_03/constituicao/constituicao.htm Acesso em 18 de agosto de 2020.

Facebook de Alison Bernardino. Disponível em: https:/www.facebook.com/alison.bernardino.56/videos/ 215713659747357/UzpfSTEwMDAxMDA4MDk2MjUyOToxMTA1MDY0NzE5ODM5NTUw/?lst=1125865 838\%3A100010080962529\%3A159179811 Acesso em 26 jun. 2020

FOUCAULT, Michel. Em Defesa da Sociedade [1976]. $3^{a}$ tiragem. São Paulo, SP. Martins Fontes, 2005.

FRIEDRICH, Otto. O Fim do Mundo. Rio de Janeiro RJ: Record, 2000.

FURTADO, Rafael N; CAMILO, Juliana A. O conceito de biopoder no pensamento de Michel Foucault. Revista Subjetividades. v.16, n. 3, 2016. Disponível em: http://pepsic.bvsalud.org/scielo.php?script=sci_arttext\&pid=S2359-07692016000300003 Acesso em 05/06/2020

GARCIA, Gustavo; GOMES, Pedro Henrique; VIANA, Hamanda. 'E daí? Lamento. Quer que eu faça o quê?', diz Bolsonaro sobre mortes por coronavírus; 'Sou Messias, mas não faço milagre'. Disponível em: https:// g1.globo.com/politica/noticia/2020/04/28/e-dai-lamento-quer-que-eu-faca-o-que-diz-bolsonaro-sobremortes-por-coronavirus-no-brasil.ghtml Acesso em: 25 maio 2020.

GRIGOLETTO, Evandra. Do lugar social ao discursivo: o imbricamento de diferentes posições sujeito. In: SEMINÁRIO DE ESTUDOS EM ANÁLISE DO DISCURSO. UFRGS, 2005, Porto Alegre. Anais eletrônicos. Porto Alegre: UFRGS, 2005, p. 154-164. Disponível em: http://www.ufrgs.br/analisedodiscurso/anaisdosead/ 2SEAD/SIMPOSIOS/EvandraGrigoletto.pdf. Acesso em: maio de 2019.

HENRY, Paul. A história não existe? In: ORLANDI, Eni P. (Org.). Gestos de leitura. Campinas: Editora da Unicamp, 1997. p. 23-47.

MARIANI, Bethania. As formas discursivas e a ameaça comunista. Revista Língua e Instrumentos Linguísticos, Campinas, SP, n. 44, jul./dez. 2019. p. 270-289. DOI: 10.20396/lil.v0i44.8657817

MITTMANN, Solange. Heterogeneidade construtiva, contradição histórica e sintaxe. Revista do Programa de Pós-Graduação em Letras da Universidade de Passo Fundo. v. 6, n.1. jan./jun. 2010. p. 85-101.

ORLANDI, Eni P. As formas do silêncio: no movimento dos sentidos. Campinas, SP: Editora da Unicamp, 1993.

ORLANDI, Eni. P. Discurso e Texto. 2.ed. Campinas, Pontes, 2005. 
ORLANDI, Eni P. Discurso e Texto: formulação e circulação dos sentidos. $4^{a}$ edição. Campinas, SP: Pontes, 2012.

ORLANDI, Eni P. Análise de Discurso: princípio e procedimentos. 12ª edição. Campinas, SP: Pontes, 2015. PÊCHEUX, Michel. O Discurso - estrutura ou acontecimento. 3.ed. Campinas: Pontes, 2002.

PÊCHEUX, Michel. Semântica e Discurso: uma crítica à afirmação do óbvio. Tradução: Eni Puccinelli Orlandi et al. $5^{\text {a }}$ ed. Campinas, SP: Editora da Unicamp, 2014.

PÊCHEUX, Michel. A aplicação dos conceitos da linguística para a melhoria das técnicas de análise de conteúdo. In: Análise de Discurso: Michel Pêcheux. Textos escolhidos por: Eni Orlandi 4. ed. Campinas, SP: Pontes Editores, 2015. 